\title{
Information giving and receiving in hematological malignancy consultations
}

\section{Citation}

Alexander, Stewart C., Amy M. Sullivan, Anthony L. Back, James A. Tulsky, Roberta E. Goldman, Susan D. Block, Susan K. Stewart, Maureen Wilson-Genderson, and Stephanie J. Lee. 2011. "Information Giving and Receiving in Hematological Malignancy Consultations." PsychoOncology 21 (3) (February 4): 297-306. doi:10.1002/pon.1891.

\section{Published Version}

doi:10.1002/pon.1891

\section{Permanent link}

http://nrs.harvard.edu/urn-3:HUL.InstRepos:32295307

\section{Terms of Use}

This article was downloaded from Harvard University's DASH repository, and is made available under the terms and conditions applicable to Other Posted Material, as set forth at http:// nrs.harvard.edu/urn-3:HUL.InstRepos:dash.current.terms-of-use\#LAA

\section{Share Your Story}

The Harvard community has made this article openly available.

Please share how this access benefits you. Submit a story.

\section{Accessibility}




\title{
Information giving and receiving in hematological malignancy consultations ${ }^{\dagger}$
}

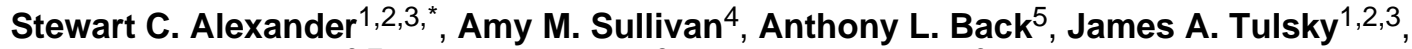 \\ Roberta E. Goldman ${ }^{6,7}$, Susan D. Block ${ }^{8}$, Susan K. Stewart ${ }^{9}$, Maureen Wilson-Genderson ${ }^{10}$, \\ and Stephanie J. Lee ${ }^{11}$ \\ ${ }^{1}$ Center for Health Services Research, Durham VA Medical Center, Durham, NC, USA \\ ${ }^{2}$ Center for Palliative Care, Duke University Medical Center, Durham, NC, USA \\ ${ }^{3}$ Department of Medicine, Duke University Medical Center, Durham, NC, USA \\ ${ }^{4}$ Beth Israel Deaconess Medical Center, Department of Medicine, Harvard Medical School, \\ Boston, MA, USA \\ ${ }^{5}$ Department of Medicine, University of Washington, Washington, DC, USA \\ ${ }^{6}$ Department of Family Medicine, Warren Alpert Medical School of Brown University, Providence, \\ RI, USA \\ ${ }^{7}$ Department of Society, Human Behavior and Health, Harvard School of Public Health, Ann \\ Arbor, MI, USA \\ ${ }^{8}$ Department of Psychosocial Oncology and Palliative Care, Dana-Farber Cancer Institute and \\ Brigham and Women's Hospital, Harvard Medical School, Boston, MA, USA \\ ${ }^{9}$ Blood and Marrow Transplant Information Network, Duarte, CA, USA \\ ${ }^{10}$ Department of Social and Behavioral Health, Virginia Commonwealth University, Richmond, \\ VA, USA \\ ${ }^{11}$ Fred Hutchinson Cancer Research Center, Division of Clinical Research, Seattle, WA, USA
}

\begin{abstract}
Purpose-Little is known about communication with patients suffering from hematologic malignancies, many of whom are seen by subspecialists in consultation at tertiary-care centers. These subspecialized consultations might provide the best examples of optimal physician-patient communication behaviors, given that these consultations tend to be lengthy, to occur between individuals who have not met before and may have no intention of an ongoing relationship, and which have a goal of providing treatment recommendations. The aim of this paper is to describe and quantify the content of the subspecialty consultation in regards to exchanging information and identify patient and provider characteristics associated with discussion elements.
\end{abstract}

Methods-Audio-recorded consultations between 236 patients and 40 hematologists were coded for recommended communication practices. Multilevel models for dichotomous outcomes were created to test associations between patient, physician and consultation characteristics and key discussion elements.

\footnotetext{
${ }^{\dagger}$ Results were previously presented at the American Society of Hematology Annual Meeting 2009.

Copyright (C) 2011 John Wiley \& Sons, Ltd.

${ }^{*}$ Correspondence to: Center for Palliative Care, Duke University Medical Center, Hock Plaza, Suite 1105, 2424 Erwin Road, Durham, NC 27705, USA. alexa045@mc.duke.edu.
} 
Results-Discussions about the purpose of the visit and patient's knowledge about their disease were common. Other elements such as patient's preference for his/her role in decision-making, preferences for information, or understanding of presented information were less common. Treatment recommendations were provided in $97 \%$ of the consultations and unambiguous presentations of prognosis occurred in $81 \%$ of the consultations. Unambiguous presentations of prognosis were associated with non-White patient race, lower educational status, greater number of questions asked, and specific physician provider.

Conclusion-Although some communication behaviors occur in most consultations, others are much less common and could help tailor the amount and type of information discussed. Approximately half of the patients are told unambiguous prognostic estimates for mortality or cure.

\section{Keywords}

communication; physician-patient encounters; oncology; hematology; prognosis; cancer

\section{Introduction}

Guidelines for effective physician-patient communication consistently include several key elements: establishing the purpose of the visit, eliciting patient preferences for disclosure of medical information and involvement in decision-making, reviewing treatment options and recommendations, and checking for patient' comprehension [1-9]. The extent to which physicians actually practice these behaviors when communicating with different patient groups is largely unknown.

Our study focused on initial subspecialty consultations for patients with hematological malignancies. This setting was selected because: (1) little is known about communication with patients diagnosed with hematologic malignancies, many of whom are potentially eligible for hematopoietic cell transplantation, a risky but potentially curative procedure; and (2) subspecialty consultations are viewed as opportunities to summarize patient diagnosis and prognosis and provide expert treatment recommendations. The subspecialty consultation often is longer, more detailed, and more clearly focused on treatment options and medical decision-making than a routine hematology or oncology visit [10]. Furthermore, this indepth evaluation is provided, often in a single visit, by a physician with no previous relationship with the patient. These features suggest that subspecialty consultations might have a higher frequency of the recommended information giving and receiving communication behaviors than other settings.

The aims of this paper are to describe and quantify the content of the subspecialty consultation with regard to exchanging information and identify patient and provider characteristics associated with these discussion elements.

\section{Methods}

\section{Participants}

Patient and physician study participants were recruited as part of the HEMA-COMM study, a four-site study including the Dana-Farber Cancer Institute, Massachusetts General Hospital, Massey Cancer Center, and Fred Hutchinson Cancer Research Center. The study was approved by the Institutional Review Boards of the participating institutions, and all patient and physician participants provided written consent. Only participants from the Dana-Farber Cancer Institute $(n=95)$ and Fred Hutchinson Cancer Research Center $(n=141)$ with audio-recorded consultations are included in this analysis because the other centers did not provide sufficient patients to control for center effect. 


\section{Physicians}

Ninety-four physicians from two tertiary-care medical centers were approached for the study. Physicians were eligible for participation if they saw at least 12 new patients with hematologic malignancies annually. Ninety-one physicians (97\% of those approached) agreed to participate and signed informed consent, although one subsequently withdrew consent to enroll additional patients (use of already collected data was allowed).

\section{Patients}

Patients were eligible for participation if they were scheduled for a consultation with a physician participating in the study, this was their first visit with the physician, were diagnosed with a hematologic malignancy, and were able to communicate in English. If more than the required number of patients were eligible in a particular week, patients were prioritized so that under-represented races/ethnicities and physicians were approached. Recruitment occurred from September 2003 through June 2007.

\section{Survey measures}

After physicians and patients were enrolled, they completed a baseline survey prior to the consultation that collected sociodemographic data and other baseline information.

\section{Audio recordings and consultation codes}

Digital recorders were placed in unobtrusive locations in the exam rooms before the physicians and patients entered and were retrieved at the end of the visit. If the consultation was delayed or the physician stepped out of the room during the consultation, those sections were deleted prior to analysis.

The length of the consultation and number of medically related questions asked by patients and others who accompanied patients to their visits were captured. A communication evaluation tool was developed to measure the components of physician- patient verbal interaction during the consultation. The tool was developed a priori from the empirical literature and accepted practice standards [2,4,5,11-26]. A codebook was developed to provide specific instructions for coding each topic with precise definitions of what should and should not be coded along with numerous examples. Coders coded the consultations for specific communication topics, referred to as segments, which could range from a phrase to several minutes of discussion, depending on how long the discussion about a particular topic continued uninterrupted. This method of coding communication segment has been used in multiple studies of physician-patient communication [1,6,9,27-30].

Communication segments consisted of four main conceptual areas: (1) framing the consultation, (2) presenting prognostic information, (3) discussing treatment options, and (4) other topics. Table 1 summarizes detailed codes, definitions, and examples. Framing the consultation consisted of: discussing the purpose of the visit, assessing patient's prior knowledge about his/her disease, eliciting patient preference for information, and eliciting patient preference for role in decision-making. Physicians, patients, or support people might have initiated these discussions. Presenting prognostic information consisted of: discussing mortality, discussing chance of cure, giving qualitative prognostic information, giving quantitative prognostic information, and 'hedging' (i.e. suggesting that presented statistics might not apply to the patient). Discussing treatment options consisted of: discussing the specific treatment goal of cure, discussing the specific treatment goal of palliation, discussing the specific treatment goal of extending life, providing a treatment recommendation, discussing the impact of treatment on the patient's quality of life, discussing the patient's participation in recovery, and discussing a specific type of treatment goal (i.e. cure, palliation, or extending life). Finally, other topics included: discussing 
complementary or alternative medicine, discussing clinical trials, and checking patient's understanding of information.

\section{Coder training}

Four coders evaluated the encounters by listening to the digitally audio-recorded conversations. Coders were rigorously trained on the identification of specific communication segments and application of specific codes. Training consisted of $80 \mathrm{~h}$ over a 4-week time period.

Coders underwent a step-by-step process of learning the codes. The training process was organized so that coders gained confidence and reliability as they gained independence. The training instructor began with a review of the code-book and gave examples of each segment. The coders generated their own examples of each segment and then reviewed precoded conversations selected for both good and poor demonstrations of each segment to ensure that coders captured both better and worse ways of discussing a topic. The coders then 'team-coded', listening to conversations together and recording the presence of segments. Finally, the coders were given individual conversations to code, and the training instructor reviewed conversations and segments biweekly with coders. This form of intensive training contributed significantly to the high reliabilities.

Coders re-coded a random sample of $20 \%$ of all audio recordings $(n=49)$ to obtain inter-rater reliability of the coding system. Cohen's Kappa was used to calculate inter-rater reliability for each segment using Landis and Koch's classification [31]. Four topics received near perfect, nine topics received substantial, and one topic had moderate agreement (Table 2).

\section{Biostatistical analysis}

Descriptive analyses were performed for physician and patient characteristics and consultation segments. Our choices of specific analytic variables related to physician [32], patient $[33,34]$, and consultation characteristics [35-38] were based on the findings from prior research, showing these to be associated with communication processes or outcomes.

Prognostic discussions are reported in two ways: first as the percentage of consultations in which each segment (i.e. discussion about likelihood of cure, discussion about mortality, qualitative prognosis, quantitative descriptions, and hedging) occurred and, second, as an aggregate variable that categorized conversations hierarchically considering both type of prognostic information (quantitative vs qualitative prognostic information) and whether hedging occurred. 'Unambiguous prognostic discussions' were considered those in which a quantitative estimate was provided with either a point estimate or a range using percentages, fractions or specific time estimates for mortality or cure. For each unambiguous prognostic discussion, the presence or absence of 'hedging' was noted. Consultations were classified hierarchically as: only quantitative discussion(s) of prognosis (related to cure or mortality) occurred without hedging; quantitative discussion(s) of prognosis occurred both with and without hedging; quantitative discussion(s) of prognosis occurred but always with hedging; prognosis discussed qualitatively only or not discussed at all. This hierarchy is based on the precision of the prognostic information provided and lack of ambiguity rather than a judgment about the best ways to communicate information.

Multilevel models for dichotomous outcomes were created using HLM 6.04. Level one models included patient characteristics including: sex, education (less than college, college or higher education), race (White, non-White), age (less than 55 years (median), 55 years and above), marital status (married vs not married), income (dichotomized at the median), the number of questions asked during consultation (dichotomized at the median), and conversation length. Level two physician variables included physician (to account for 
nesting of patients within doctors), age, sex, the number of new patients per month, and year completed fellowship. With the exception of physician and physician sex, all physician variables were nonsignificant and were dropped from the subsequent models. Separate models were created for each outcome.

\section{Results}

\section{Sample demographics}

Physicians-Ninety-one physicians agreed to be part of the study. Of these, 40 (44\%) subsequently had consultations with between 1 and 16 enrolled patients (Table 3); the others did not have a participating patient. Eighteen physicians (45\%) were from the Dana-Farber Cancer Institute and 22 physicians (55\%) were from the Fred Hutchinson Cancer Research Center. Physicians were predominantly male $(85 \%)$ with a median age of 47 years. The median number of new patient consultations per month was $8($ range $=2-30)$ by physician self-report.

Patients-Two hundred and thirty-six patients participated in the study (Table 4). One hundred and twenty-six patients were male (53\%). Patients were predominately White $(89 \%)$ and were either married or living with a partner (78\%). The median age was 55 years and approximately half were college graduates. The median time from diagnosis to the consultation was 3.8 months. The most common diagnoses were lymphoma, acute leukemia, myelodysplastic syndrome, multiple myeloma, and chronic leukemia. Approximately, half (47\%) planned to obtain care at the consulting institution, whereas $43 \%$ planned to obtain a second opinion and then intended to return to their local physicians for care. The rest were undecided or listed both goals (10\%).

\section{Description of conversations}

The median duration of consultations where the physician and patient were in the room together was approximately $80 \mathrm{~min}$ (range $=15-152 \mathrm{~min}$ ).

Framing the consultation-Discussions about the purpose of the visit $(78 \%)$ and patient's prior knowledge about their disease (89\%) were common. Other elements such as formally establishing patient' preferences for the consultation were seen infrequently, although discussions about the patients' preferences for decision-making (37\%) were more common compared to discussions about preferences for information (5\%) (Table 5).

Presenting prognostic information-Discussions about prognosis for mortality and cure were common. These prognostic messages were presented both qualitatively (97\% of all consultations, median 14 segments per discussion) and quantitatively (90\% of consultations, median six segments per discussion). Qualitatively, most messages were either in descriptive words ('things don't look that good') or in personal stories ('my longest person without any active myeloma is 20 years'). Quantitatively, physicians provided information as percentages, fractions, and specific time estimates, with $80-85 \%$ of conversations including point estimates and/or number ranges. This large amount of prognostic information addressed both mortality and chance for cure and sometimes combined both. In total, $64 \%$ of conversations contained prognostic discussions where information about possible mortality was presented quantitatively without any 'hedging'. In $9 \%$ of consultations, quantitative prognostic information about mortality was discussed, both with and without hedging, and in 5\% of consultations; quantitative prognostic information about mortality was presented but always with hedging. In $22 \%$ of consultations, mortality was not discussed using numbers or not discussed at all. 
Discussion about potential cure of the hematologic malignancy was quantitatively discussed without any hedging in $50 \%$ of consultations, but was not discussed quantitatively or at all in $49 \%$ of consultations (Table 5).

One hundred ninety-one (81\%) consultations contained at least one quantitative prognosis of either mortality or cure, whereas 45 (19\%) did not address either issue or did so only with hedging. Seventy percent $(n=166)$ of consultations contained only quantitative prognostic discussions without any qualitative discussions or hedging.

Discussion of treatment options-Overall, almost all conversations contained discussions about treatment, with over $97 \%$ of hematologists-oncologists, providing at least one explicit recommendation (' We should get started with thalidomide and dexamethasone in the next few weeks'). Often, these recommendations were made based on future possible contingencies (e.g. 'if there is Helicobacter pylori there and we don't want to cut out your stomach, it leaves us with either treating it or doing the radiation. If the bacteria is not there, it is easy, we do the radiation, if the bacteria is there, that is more difficult-we could try to see if it responds to antibiotics or even quadruple therapy.'). Physicians discussed treatments in relation to both curative goals ( $72 \%$ of conversations) (" what takes to cure it is a bone marrow/stem cell transplant and with eight brothers and sisters, you are likely to have someone who will be a match for you') as well as extending life (22\%) ('that is a condition we can manage for many, many years with these drugs'). Rarely physicians and patients did discuss treatments in terms of palliative care (6\%). When palliation discussions did come up, they were often discussed as an option if other treatments failed and thus were often discussed very briefly and vaguely. It was rare for patients and physicians to discuss what role patients could play in recovery (less than 1\%) (Table 5).

Other topics-Discussions about clinical trials were common (78). In $25 \%$ of the consultations, complementary and/or alternative medicine was discussed. In less than onethird of the consultations (31\%), physicians checked patient's understanding of information with mean of 0 number of checks (range $=0-5$ ). Finally, patients and their support people asked a median of 23 questions during the consultations with a range of $0-78$ questions.

\section{Predictors of consultation components}

Table 6 summarizes significant patient, physician, and consultation factors associated with specific discussion topics. Discussion about patients' preferences for their role in decisionmaking was more likely if patients were unmarried $(p=0.015)$ and the conversation was longer than average $(p=0.01)$. Discussion about treatment impact on patients' quality of life was more likely if the patient and support person asked more questions than average $(p=0.34)$. Quantitative prognostic discussion about mortality without hedging was associated with lower patient education $(p=0.01)$ and more than average number of questions asked by the patient/support person $(p=0.039)$ but was most clearly associated with physician seen $(p=0.001)$. Quantitative prognostic discussion about cure without hedging was associated with non-White patient race ( $p=0.018)$, lower education $(p=0.016)$, and higher number of questions asked ( $p=0.007)$. There were no factors associated with whether a physician checked for patient understanding of information presented or with discussions about the purpose of the visit. There were too few cases of discussion about patient' preference for information to create a model.

\section{Discussion}

We analyzed 236 initial subspecialty consultations between hematologists-oncologists and their patients with hematological malignancies and report several key results. First, although 
hematologists-oncologists devote a long time to these consultations and provide a large amount of information, they tend to underutilize many communication behaviors that may enhance the usefulness of the consultation. These include establishing the patient's preference for information and decision-making role, and checking patients' understanding of presented information. Second, subspecialists are discussing difficult content with patients they have never met before, specifically providing quantitative estimates of mortality and cure without any hedging in at least half of the encounters. Quantitative prognostic discussions without hedging are more likely to occur if the patients are nonWhite, of lower educational status, or ask more questions.

In this highly specialized type of encounter, hematologist-oncologists are spending a long time with patients and covering a large amount of information. The median duration of these consultations was $80 \mathrm{~min}$, much longer than the typical 20-30 min encounters reported in other studies [7,15,29,39-41]. Most consultations addressed treatment goals, treatment recommendations, and provided prognostic information both qualitatively and quantitatively. Patients and physicians also frequently discussed the purpose of the visit, the patient's prior knowledge about their disease, and clinical trials. The lower frequency of discussion about the patient's preferred role in decision-making and checking patient's understanding of information are consistent with other studies [1,15,27,40,42]. The literature suggests that a greater attempt by physicians to establish patient' preference for information type and detail and to understand their preferred decision-making role would allow the consultation to be better tailored to the patient's needs [4,11]. Although physicians may be able to garner this information indirectly during the course of the consultation, explicit discussion of these issues gives the patient a chance to express his or her preferences and demonstrates respect for the patient's role, and needs during the consultation. Asking about preferences can set the tone for the consultation although the interactions may subsequently evolve. Greater efforts to check patient' understanding of presented information would help physicians know how much of the conversation is being absorbed $[43,44]$. We found it surprising that patients and physicians almost never discussed how patients can participate in their recovery. Only half discussed how treatment would impact quality of life. This may be because treatment decisions had not been made yet, or because physicians do not address such topics unless directly asked about this by patients.

We found that $81 \%$ of consultations contained at least one quantitative discussion of prognosis without any hedging. Conversely, in cases where physicians either presented only qualitative prognostic information, used hedging techniques or did not address prognosis, the reasons for avoiding unambiguous prognostic discussions are not known. All consultations occurred between patients and physicians who had not previously met each other, suggesting that difficult topics might be avoided. Hedging may allow physicians to fulfill their duty to reveal prognosis but soften the news and allow patients to think they will do much better than average. It may be that prognosis is not known for some patients, or that patients directly or indirectly expressed a preference to avoid prognostic information. Physicians themselves may have felt uncomfortable with prognostic discussions. The literature suggests that all these mechanisms likely have a role.

We were able to identify several patient' characteristics that were associated with specific discussion elements, suggesting that patients are either actively eliciting or passively prompting these discussions. For example, it is not surprising that patients who ask more questions are more likely to hear about the impact of treatment on quality of life, or to hear quantitative estimates of mortality, and cure without hedging. Question asking may be one of the ways that patients signal the level of their information needs to physicians, and physicians may modify their behavior in response to the topics and sophistication of the questions. It is less clear why the discussions of preference for decision-making role would 
arise when patients are unmarried or why lower patient education is associated with provision of quantitative estimates of mortality and cure without hedging. We hypothesize that physicians may have felt a greater need for clarity with these patients.

There are several limitations to our study. First, the study analyzed data from only two sites, which are both large tertiary institutions; therefore, it may not be possible to generalize the findings to physicians at other sites. For example, we suspect that consultations of this duration may be less common in other settings. Second, we examined only verbal communication, thus nonverbal behaviors that might influence the interaction were not captured. Third, physicians knew that they were being audio recorded for a study of physician-patient communication. However, the literature supports that physicians do not substantially modify their communication behavior in response to observation $[19,45]$. Finally, because our patient sample was $89 \%$ White, findings of potential differences in physician communication with White vs non-White patients are only preliminary and need to be tested in a sample with larger proportions of non-White patients.

Our data set provides a rich trove of information about the interactions between physicians and patients in subspecialty consultations, and we plan many future analyses, several of which include a focus on communication behaviors and prognostic beliefs. For example, we plan to analyze the factors associated with concordant prognostic estimates between patients and physicians. We will also examine the impact of prognostic discussions on prognostic understanding and psychological status. Other analyses focus on information needs, information receipt, and satisfaction; and treatment decision-making. Our ultimate goal is to help physicians use the best communication practices to optimize their interactions with patients during subspecialty consultations by linking communication behaviors to patient outcomes.

In summary, hematologist-oncologists in our study spent a long time with patients and discussed many recommended topics including likelihood of death and cure during their initial subspecialty consultations, but did not utilize many communication behaviors that have been recommended in the literature. Several of these topics, such as preference for information, preference for decision-making role, and checking for patient understanding of presented information, take relatively little time to discuss and might have helped tailor the consultation even more to the patients' specific needs.

\section{Acknowledgments}

The authors wish to thank all the physicians and patients who participated in this study, and the study project managers: Christina Caron, Arnold Gonzales, Tarrah Kirkpatrick, M. Shannon Hill, and Kate Chilson. This work was supported by CA 098486 from the National Cancer Institute. Designed research and drafted the manuscript (S. C. A., A. S., S. J. L.), performed the statistical analysis (A. S., M. W. G.), interpreted data and critically revised the manuscript (S. C. A., A. S., A. L. B., J. A. T., R. E. G., S. B., S. K. S., S. J. L.). Dr. Alexander was supported by Health Services Research Career Development Award RCD 07-006 from the Department of Veterans Affairs. The authors have no conflicts of interest to declare.

\section{References}

1. Alexander S, Keitz S, Sloane R, Tulsky J. A controlled trial of a short course to improve medical house staff communication with patients at the end of life. Acad Med. 2006; 81:1008-1012. [PubMed: 17065871]

2. Back AL, Arnold RM, Tulsky JA, Baile WF, Fryer-Edwards KA. Teaching communication skills to medical oncology fellows. J Clin Oncol. 2003; 21:2433-2436. [PubMed: 12805343]

3. Back AL, Curtis JR. Communicating bad news. West J Med. 2002; 176:177-180. [PubMed: 12016241] 
4. Baile WF, Buckman R, Lenzi R, Glober G, Beale EA, Kudelka AP. SPIKES-A six-step protocol for delivering bad news: application to the patient with cancer. Oncologist. 2000; 5:302-311. [PubMed: 10964998]

5. Baile WF, Kudelka AP, Beale EA, et al. Communication skills training in oncology. Description and preliminary outcomes of workshops on breaking bad news and managing patient reactions to illness. Cancer. 1999; 86:887-897. [PubMed: 10463990]

6. Bylund CL, Brown RF, Gueguen JA, Diamond C, Bianculli J, Kissane D. The implementation and assessment of a comprehensive communication skills training curriculum for oncologists. PsychoOncology. 2010; 19:583-593. [PubMed: 19484714]

7. Dimoska A, Butow PN, Dent E, et al. An examination of the initial cancer consultation of medical and radiation oncologists using the Cancode interaction analysis system. Br J Cancer. 2008; 98:1508-1514. [PubMed: 18454160]

8. Baile WF, Glober GA, Lenzi R, Beale EA, Kudelka AP. Discussing disease progression and end-oflife decisions. Oncology. 1021; 13:1021-1031. [PubMed: 10442349]

9. Brown R, Bylund CL, Eddington J, Gueguen JA, Kissane DW. Discussing prognosis in an oncology setting: initial evaluation of a communication skills training module. Psycho-Oncology. 2010; 19:408-414. [PubMed: 19441006]

10. Graugaard PK, Holgersen K, Eide H, Finset A. Changes in physician-patient communication from initial to return visits: a prospective study in a haematology outpatient clinic. Patient Edu Coun. 2005; 57:22-29.

11. Back AL, Arnold RM, Baile WF, Tulsky JA, Fryer-Edwards K. Approaching difficult communication tasks in oncology. CA Cancer J Clin. 2005; 55:164-177. [PubMed: 15890639]

12. Baile, W. Practice Guidelines for Patient/Physician Communication: Breaking Bad News, version 1.01. National Comprehensive Cancer Network; Rockledge, PA: 2000.

13. Baile WF, Lenzi R, Kudelka AP, et al. Improving physician-patient communication in cancer care: outcome of a workshop for oncologists. J Cancer Educ. 1997; 12:166-173. [PubMed: 9376255]

14. Branch WT, Malik TK. Using 'windows of opportunities' in brief interviews to understand patients' concerns. J Am Med Assoc. 1993; 269:1667-1668.

15. Butow PN, Brown RF, Cogar S, Tattersall MH, Dunn SM. Oncologists' reactions to cancer patients' verbal cues. Psycho-Oncology. 2002; 11:47-58. [PubMed: 11835592]

16. Clever SL, Tulsky JA. Dreaded conversations: moving beyond discomfort in patient-physician communication. J Gen Intern Med. 2002; 17:893-894.

17. Eide H, Frankel R, Haaversen AC, Vaupel KA, Graugaard PK, Finset A. Listening for feelings: identifying and coding empathic and potential empathic opportunities in medical dialogues. Patient Educ Couns. 2004; 54:291-297. [PubMed: 15324980]

18. Fischer, GS.; Tulsky, JA.; Arnold, RM., editors. Communicating A Poor Prognosis. Oxford University Press; New York: 2000.

19. Inui TS, Carter WB, Kukull WA, Haigh VH. Outcome-based doctor-patient interaction anaylsis: I. Comparison of techniques. Med Care. 1982; 20:535-549. [PubMed: 7109738]

20. Levinson W, Gorawara-Bhat R, Lamb J. A study of patient clues and physician responses in primary care and surgical settings. J Am Med Assoc. 1021; 284:1021-1027.

21. Maguire P. Barriers to psychological care of the dying. Br Med J (Clin Res Ed). 1985; 291:17111713.

22. Maguire P, Faulkner A, Booth K, Elliott C, Hillier V. Helping cancer patients disclose their concerns. Eur J Cancer. 1996; 32A:78-81. [PubMed: 8695247]

23. Rimal RN. Analyzing the physician-patient interaction: an overview of six methods and future research directions. Health Commun. 2001; 13:89-99. [PubMed: 11370926]

24. Roter, D.; Hall, JA. Doctors Talking With Patients/Patients Talking With Doctors: Improving Communication in Medical Visits. Auburn House; Westport, CT: 1992.

25. Smith R, Hoppe R. The patient's story: integrating the patient- and physician-centered approaches to interviewing. Ann Intern Med. 1991; 115:470-477. [PubMed: 1872495]

26. Suchman AL, Markakis K, Beckman HB, Frankel R. A model of empathic communication in the medical interview. J Am Med Assoc. 1997; 277:678-682. 
27. Back AL, Arnold RM, Baile WF, et al. Efficacy of communication skills training for giving bad news and discussing transitions to palliative care. Arch Intern Med. 2007; 167:453-460. [PubMed: 17353492]

28. Kennifer S, Alexander S, Pollak K, et al. Negative emotions in cancer care: do oncologists' responses depend on severity and type of emotion? Patient Edu Couns. 2009; 76:51-56.

29. Pollak K, Arnold R, Jeffreys A, et al. Oncologist communication about emotion during visits with advanced cancer patients. J Clin Oncol. 2007; 25:48-52.

30. Robinson T, Alexander S, Hays M, et al. Patientoncologist communication in advanced cancer: predictors of patient perception of prognosis. Support Care Cancer. 2008; 16:803-811. [PubMed: 17960430]

31. Landis JR, Koch GG. The measurement of observer agreement for categorical data. Biometrics. 1977; 33:159-174. [PubMed: 843571]

32. Keating N, Landrum M, Rogers SJ, et al. Physician factors associated with discussions about endof-life care. Cancer. 2010; 15:998-1006. [PubMed: 20066693]

33. Rose J, O’Toole E, Einstadter D, Love T, Shenko C, Dawson N. Patient age, well-being, perspectives, and care practices in the early treatment phase for late-stage cancer. J Gerontol A Biol Sci Med Sci. 2008; 63:960-980. [PubMed: 18840801]

34. Pollak KI, Arnold R, Jeffreys A, et al. Oncologist communication about emotion during visits with patients with advanced cancer. J Clin Oncol. 2007; 25:5748-5752. [PubMed: 18089870]

35. Lee Char S, Evans L, Malvar G, White D. A randomized trial of two methods to disclose prognosis to surrogate decision makers in ICUs. Am J Respir Crit Care Med. 2010; 182:905-909. [PubMed: 20538959]

36. Butow PN, Dowsett S, Hagerty R, Tattersall MH. Communicating prognosis to patients with metastatic disease: what do they really want to know? Support Care Cancer. 2002; 10:161-168. [PubMed: 11862506]

37. Man-Son-Hing M, O’Connor A, Drake E, Biggs J, Hum V, Laupacis A. The effect of qualitative vs. quantitative presentation of probability estimates on patient decision-making: a randomized trial. Health Expect. 2002; 5:246-255. [PubMed: 12199663]

38. White D, Engelberg R, Wenrich M, Lo B, Curtis J. The language of prognostication in intensive care units. Med Decis Making. 2010; 30:76. [PubMed: 18753685]

39. Fallowfield L, Jenkins V, Farewell V, Saul J, Duffy A, Eves R. Efficacy of a Cancer Research UK communication skills training model for oncologists: a randomised controlled trial. Lancet. 2002; 359:650-656. [PubMed: 11879860]

40. Fallowfield L, Jenkins V, Farewell V, Solis-Trapala I. Enduring impact of communication skills training: results of a 12-month follow-up. Br J Cancer. 2003; 89:1445-1449. [PubMed: 14562015]

41. Jansen J, Butow PN, van Weert JCM, et al. Does age really matter? Recall of information presented to newly referred patients with cancer. J Clin Oncol. 2008; 26:5450-5457. [PubMed: 18936478]

42. Knox R, Butow PN, Devine R, Tattersall MH. Audiotapes of oncology consultations: only for the first consultation? Ann Oncol. 2002; 13:622-627. [PubMed: 12056714]

43. Amalraj S, Starkweather C, Nguyen C, Naeim A. Health literacy, communication, and treatment decision-making in older cancer patients. Oncology (Williston). 2009; 23:369-375.

44. Gabrijel S, Grize L, Helfenstein E, et al. Receiving the diagnosis of lung cancer: patient recall of information and satisfaction with physician communication. J Clin Oncol. 2008; 26:297-302. [PubMed: 18182671]

45. Korsch BM, Gozzi EK, Francis V. Gaps in doctor-patient communication. 1. Doctor-patient interaction and patient satisfaction. Pediatrics. 1968; 42:855-871. [PubMed: 5685370] 
Table 1

Codebook definitions and examples

\begin{tabular}{lll}
\hline Topic & Definition & Example \\
\hline Purpose of visit & $\begin{array}{l}\text { Any discussion about reason for } \\
\text { visit }\end{array}$ & $\begin{array}{l}\text { MD: 'Can you tell me why you came to us today?' } \\
P T: \text { 'I came here to get a second opinion about my CLL.' }\end{array}$ \\
Prior knowledge about disease & $\begin{array}{l}\text { Any discussion about what the } \\
\text { patient currently understands about } \\
\text { their illness or its treatment }\end{array}$ & $\begin{array}{l}\text { MD: 'I was wondering if you could tell me in your own } \\
\text { PT: 'I was told I have leukemia but I don't know what that } \\
\text { means }\end{array}$
\end{tabular}

Preference for information

Preference for role in decision-making

Prognostic discussion related to chance for cure

Prognostic discussion related to mortality

Qualitative prognostic information

Quantitative prognostic information

Hedging

Specific treatment goal of cure

Specific treatment goal of palliation

Specific treatment goal of extending life

Treatment recommendation

Impact of treatment on quality of life

Participation in recovery

Treatment goal
Any discussion about how much information a patient wants to know about their prognosis and/or its treatment

Any discussion that elicits a patient's desire for their participation in decision-making

Any discussion about the likelihood of cure

Any discussion about the chance of death

Any piece of information that explains cure or life expectancy that is given without numbers. Typically either in descriptive words or story form

Any prognostic information given with the use of numbers. Quantitative information can be either discussed as a point estimate or given as a range of numbers

Refers to the physician practice of qualifying numeric data that suggest that presented statistics might not apply to the patient's situation

Any discussion about how a specific treatment would be used to cure the cancer

Any discussion about how a specific treatment would be used for palliative measures

Any discussion about how a specific treatment would be used to extend the length of life

Any statement or discussion made by the physician that suggests a specific treatment plan

Any discussion about the effects of the treatment on the patient's quality of life

Any discussion about the ways a patient can enhance their own recovery

Any discussion about what the treatment is intended to provide
MD: 'I want to make sure I respect your wishes in regards to how much information you want to know about your illness.

How much detail do you want me to provide you concerning your disease?'

MD: 'We have a number of options we can do to treat your MDS, I was wondering how you want us to proceed?' PT: 'I want to make sure I get a chance to make some of the important decisions,

MD: 'If you respond well to the chemotherapy, I think your chance of cure is $60-70 \%$.'

PT: 'If we do this, does this mean I can be cured?'

MD: 'This tends to be a very difficult disease to treat, and we have to be very aggressive with it. Even with our best treatments, $50 \%$ of people will die of this disease,

MD: 'I had a patient with your same disease who underwent the same treatment I am recommending to you and that was five years ago and I just saw him the other day in my office and he is looking great'

MD: 'The scans look very promising'

MD: 'The chances are slim'

MD: 'There is a $20-40 \%$ chance that we can control the myeloma'

MD: 'Typically 1/4-1/3 of people with your type of

leukemia will be alive five years from now,

MD: 'It's probably 6-12 months'

MD: 'Typically patients with this type of disease have a 20 $30 \%$ chance of remission, but, you're younger and healthier than those patients so I don't think those odds hold for you'

MD: 'Our goal here is to cure you of your disease'

MD: 'The drug we are talking about is something we give patients to help them feel more comfortable but it doesn't cure the disease'

$M D$ : 'Using these combinations of drugs can help give you a few more years'

MD: 'What I recommend is that you have a stem cell transplant using cells from your sister'

MD: 'The treatment should be mild enough that you can continue to do the things you have been always doing'

MD: 'The more you keep doing what you are already doing, the more it will help you'

MD: 'The reason we are going to go through with this treatment is because we think we can beat this leukemia' MD: 'I like to think of the type of leukemia that you have as being a chronic illness and we are going to treat your cancer 


\begin{tabular}{lll}
\hline Topic & Definition & Example \\
\hline Complementary or alternative medicine & $\begin{array}{l}\text { Any discussion about } \\
\text { nontraditional medical treatments } \\
\text { or remedies }\end{array}$ & $\begin{array}{l}\text { as a chronic illness, which means we can't cure it but we can } \\
\text { control its effects and allow you to live as long as possible' }\end{array}$ \\
Clinical trials & $\begin{array}{l}\text { Any discussion concerning specific } \\
\text { clinical trials or general requests } \\
\text { about clinical trials }\end{array}$ & $\begin{array}{l}\text { MD: 'I am not sure if you are aware or not but there is a } \\
\text { possibility that you might qualify to be part of a clinical trial } \\
\text { that the university medical center is currently doing } \\
\text { concerning' }\end{array}$ \\
& $\begin{array}{l}\text { Refers to an attempt by the } \\
\text { physician to confirm that the } \\
\text { patient has understood information } \\
\text { that was just presented }\end{array}$ & $\begin{array}{l}\text { MD: 'Can you tell me in your own words what I explained } \\
\text { to you? }\end{array}$ \\
\hline
\end{tabular}


Table 2

\section{Reliability of coding}

\begin{tabular}{lclc}
\hline Topic & Kappa $^{\boldsymbol{a}}$ & $\mathbf{9 5 \%}$ confidence interval & Percentage agreement \\
\hline Purpose of visit & 0.63 & $0.37,0.90$ & 89 \\
Prior knowledge about disease & 0.64 & $0.42,0.86$ & 85 \\
Preference for information & 0.52 & $0.21,0.83$ & 86 \\
Preference for decision-making role & 0.87 & $0.69,1.0$ & 95 \\
Treatment recommendation & 0.60 & $0.38,0.83$ & 95 \\
Impact of treatment on quality of life & 0.66 & $0.44,0.89$ & 97 \\
Participation in recovery & 0.85 & 0.70 .1 .0 & 99 \\
Treatment goal & 0.60 & $0.38,0.83$ & 87 \\
Qualitative prognostic information & 0.62 & $0.41,0.84$ & 91 \\
Quantitative prognostic information & 0.74 & $0.56,0.91$ & 98 \\
Hedging & 0.63 & $0.44,0.81$ & 97 \\
Checks for understanding & 0.63 & $0.41,0.85$ & 82 \\
Complementary/alternative medicine & 0.81 & $0.63,0.98$ & 91 \\
Clinical trials & 0.86 & $0.67,1.0$ & 94 \\
\hline
\end{tabular}

${ }^{a}$ Cohen's Kappa was used to calculate inter-rater reliability for each code using Landis and Kock's classification (0.21-0.40, fair agreement; 0.410.60 , moderate agreement; $0.61-0.80$, substantial agreement; $0.81-1.0$, near-perfect agreement) [31]. 
Table 3

Physician demographics $(n=40)$

\begin{tabular}{lc}
\hline Characteristic & \\
\hline Median age, years (range) & $47(30-70)$ \\
Men, $n(\%)$ & $34(85)$ \\
Year fellowship completed, median (range) ${ }^{a}$ & $1992(1967-2004)$ \\
Hospital region & $18(45)$ \\
$\quad$ East coast & $22(55)$ \\
$\quad$ West coast & $8(2-30)$ \\
Estimated new patients per month, median (range) ${ }^{b}$ & $80(0-100)$ \\
Estimated percentage of patients who are direct referrals, median (range) & \\
Number of consultations in the analysis, median (range) & $5(1-16)$ \\
\hline${ }^{a}$ Missing one response. & \\
${ }^{b}{ }_{\text {Missing two responses. }}$ \\
${ }^{c}$ Missing three responses.
\end{tabular}


Table 4

Patient demographics ( $N=236)$

\begin{tabular}{|c|c|}
\hline Characteristic & \\
\hline Median age, years (range) & $55(20-79)$ \\
\hline Men, $n(\%)$ & $126(53)$ \\
\hline \multicolumn{2}{|l|}{ Education, $n(\%)$} \\
\hline High school graduate or less & $36(15)$ \\
\hline Some college & $57(24)$ \\
\hline College graduate & $73(31)$ \\
\hline Postgraduate degree & $69(29)$ \\
\hline Missing & 1 \\
\hline \multicolumn{2}{|l|}{ Marital status, $n(\%)$} \\
\hline Married/engaged/living with partner & $184(78)$ \\
\hline Single, never married & $20(9)$ \\
\hline Divorced, separated & $24(10)$ \\
\hline Widowed & $7(3)$ \\
\hline Missing & 1 \\
\hline Hispanic, $n(\%)$ & $6(3)$ \\
\hline \multicolumn{2}{|l|}{ Race, $n(\%)$} \\
\hline White & $210(89)$ \\
\hline African-American & $6(3)$ \\
\hline Asian & $13(5)$ \\
\hline American Indian/Alaskan Native & $5(2)$ \\
\hline Native Hawaiian/Pacific Islander & $1(1)$ \\
\hline More than one race & $1(1)$ \\
\hline \multicolumn{2}{|l|}{ Diagnosis, $n(\%)$} \\
\hline Lymphoma & $72(31)$ \\
\hline Acute leukemia & $45(19)$ \\
\hline Myelodysplastic syndrome & $40(17)$ \\
\hline Multiple myeloma & $37(16)$ \\
\hline Chronic leukemia & $37(16)$ \\
\hline Other & $5(2)$ \\
\hline Median time from diagnosis to consult, range & 3.8 mo ( 0.1 month-21 years) \\
\hline \multicolumn{2}{|l|}{ Cancer Center } \\
\hline East coast & $95(40)$ \\
\hline West coast & $141(60)$ \\
\hline \multicolumn{2}{|l|}{ Purpose of consult, $n(\%)$} \\
\hline Continue care at the Cancer Center & $108(47)$ \\
\hline Obtain a second opinion only & $99(43)$ \\
\hline Both or undecided & $24(10)$ \\
\hline Missing & 1 \\
\hline
\end{tabular}

Psychooncology. Author manuscript; available in PMC 2012 June 18. 
Table 5

Consultation components $(N=236)$

\begin{tabular}{|c|c|c|}
\hline \multirow[t]{2}{*}{ Duration of consultation } & \multicolumn{2}{|c|}{$80 \min (15-152 \mathrm{~min})$} \\
\hline & $n(\%)$ & Median episodes (range) \\
\hline \multicolumn{3}{|l|}{ Framing the consultation } \\
\hline Purpose of visit & $185(78)$ & $1(0-4)$ \\
\hline Prior knowledge about disease & $209(89)$ & $2(0-8)$ \\
\hline Preference for information & $12(5)$ & $0(0-1)$ \\
\hline Preference for role in decision-making & $88(37)$ & $0(0-5)$ \\
\hline \multicolumn{3}{|l|}{ Presenting prognostic information } \\
\hline Qualitative prognostic information & $229(97)$ & $14(0-87)$ \\
\hline Quantitative prognostic information & $212(90)$ & $6(0-36)$ \\
\hline Point estimate & $188(80)$ & $3(0-26)$ \\
\hline Range & $200(85)$ & $3(0-21)$ \\
\hline Percentages & $194(82)$ & $4(0-25)$ \\
\hline Fractions & $90(38)$ & $0(0-7)$ \\
\hline Specific time estimates & $150(64)$ & $1(1-16)$ \\
\hline Hedging & $55(23)$ & $0(0-6)$ \\
\hline \multicolumn{3}{|l|}{ Prognostic topics } \\
\hline \multicolumn{3}{|l|}{ Mortality } \\
\hline Quantitative prognostic information without hedging & $151(64)$ & $2(0-28)$ \\
\hline Quantitative prognostic information with and without hedging & $22(9)$ & - \\
\hline Quantitative prognostic information discussed with hedging & $11(5)$ & $0(0-4)$ \\
\hline No quantitative information or not discussed & $52(22)$ & \\
\hline \multicolumn{3}{|l|}{ Cure } \\
\hline Quantitative prognostic information discussed without hedging & $119(50)$ & $1(0-9)$ \\
\hline Quantitative prognostic information discussed with and without hedging & $2(1)$ & - \\
\hline Quantitative prognostic information discussed with hedging & $0(0)$ & $0(0-2)$ \\
\hline No quantitative information or not discussed & $115(49)$ & - \\
\hline \multicolumn{3}{|l|}{ Discussing treatment options } \\
\hline Treatment recommendations & $230(97)$ & $9(0-50)$ \\
\hline Treatment impact on patient's quality of life & $122(52)$ & $1(0-9)$ \\
\hline Participation in recovery & $3(1)$ & $0(0-2)$ \\
\hline Treatment goals ${ }^{a}$ & $233(99)$ & $25(0-78)$ \\
\hline Cure & $170(72)$ & $23(0-71)$ \\
\hline Palliation & $15(6)$ & $0(0-3)$ \\
\hline Extend life & $53(22)$ & $12(0-54)$ \\
\hline \multicolumn{3}{|l|}{ Other discussion } \\
\hline Clinical trials & $183(78)$ & $2(0-11)$ \\
\hline Complementary/alternative medicine & $60(25)$ & $0(0-5)$ \\
\hline Checks for understanding & $74(31)$ & $0(0-5)$ \\
\hline
\end{tabular}


Duration of consultation

$80 \min (15-152 \mathrm{~min})$

$n(\%) \quad$ Median episodes (range)

Number of questions, median (range) $23(0-122)$

$a_{8}(3 \%)$ coded as more than one goal. 
